\title{
Effectiveness of an Educational Trial to Encourage Sufficient Calcium Intake in Women College Students
}

\author{
KAZUYO SUETA \\ Seika Women's Junior College, Fukuoka 816-8540 and Department of Public Health, \\ Kurume University School of Medicine, Kurume 830-0011, Japan
}

\begin{abstract}
Summary: An educational trial to encourage sufficient calcium $(\mathrm{Ca})$ intake was conducted on women college students who entered the college for dietitian either in 1993 or in 1994. The trial's effectiveness was assessed by a prospective cohort study. Two hundred and fifteen 18- or 19-yearold students were assigned into two cohorts, i.e., a control cohort (CC) and an educated cohort $(E C)$. Both groups received 3 surveys, i.e., at baseline, 1 week after, and 1 year after the Ca education, which was given only to the EC at baseline to encourage sufficient $\mathrm{Ca}$ intake. The amount of $\mathrm{Ca}$ taken by the $\mathrm{CC}$ did not significantly change in the 3 surveys. The EC took a significantly larger amount of $\mathrm{Ca} 1$ week after and maintained relatively larger amount of $\mathrm{Ca} 1$ year after the $\mathrm{Ca}$ education. These results suggest some effectiveness of $\mathrm{Ca}$ education on the women college students.
\end{abstract}

Key words effectiveness of educational trial, sufficient calcium intake, women college students, cohort study

\section{INTRODUCTION}

The National Nutritional Survey of Japan (NNSJ) [1] has repeatedly shown that the daily intake of calcium (Ca) by Japanese is less than the recommended dietary allowance (RDA) of $600 \mathrm{mg}$ [2]. An educational approach may be a potential method to solve the problem, however, there are few studies evaluating such methods [3-5]. Women college students for dietitian may be a population relatively susceptible to change attitude in response to a $\mathrm{Ca}$ education $(\mathrm{CaE})$ because of their sense of profession, and an educational trial to encourage sufficient $\mathrm{Ca}$ intake on them may be one step to develop a $\mathrm{CaE}$ for a general population.

The present investigation reports the results of a $\mathrm{CaE}$ trial on women college students for dietitian. The effectiveness of the trial was assessed by a prospective cohort study.

\section{MATERIALS AND METHODS}

\section{Study design and subjects}

A similar educational trial had been performed previously by the present author. The previous study design and results were reported elsewhere [5]. The present study was characterized by modifications, with respect to the previous one, in terms of instrument, data size and analytical methods. Briefly, the present study was a prospective cohort study. Two hundred and fifteen 18- or 19-year-old women college students who were admitted to the college either in 1993 or in 1994 were assigned into two cohorts, i.e., a control cohort (CC) and an educated cohort (EC) by class of admission year. The assignment was performed blindly for the subjects. Both cohorts received 3 surveys, i.e., at the time of baseline (BL), 1 week after (1WA), and 1 year after (1YA) the $\mathrm{CaE}$ described below.

\section{Instruments}

The BL survey included a nutritional survey for 3 consecutive days by a quantitative or semi-quanti- 
TABLE 1

Profile of study subjects of each cohort at baseline

\begin{tabular}{|c|c|c|c|c|c|}
\hline \multirow[b]{2}{*}{ Characteristics } & \multirow[b]{2}{*}{ Category } & \multicolumn{2}{|c|}{ Control Cohort } & \multicolumn{2}{|c|}{ Educated Cohort } \\
\hline & & $\begin{array}{c}1993 \text { class } \\
n=54\end{array}$ & $\begin{array}{c}1994 \text { class } \\
n=54\end{array}$ & $\begin{array}{c}1993 \text { class } \\
\mathrm{n}=54\end{array}$ & $\begin{array}{c}1994 \text { class } \\
n=53\end{array}$ \\
\hline \multirow[t]{2}{*}{ Lactose intolerance } & no & $50(92.6)$ & $45(83.3)$ & $50(92.6)$ & $49(92.5)$ \\
\hline & yes & $4(7.4)$ & $9(16.7)$ & $4(7.4)$ & $4(7.5)$ \\
\hline \multirow{2}{*}{ Body mass index } & less than 20 & $18(33.3)$ & $18(33.3)$ & $15(27.8)$ & $18(34.0)$ \\
\hline & $20-25$ & $36(66.7)$ & $36(66.7)$ & $39(72.2)$ & $35(66.0)$ \\
\hline \multirow[t]{2}{*}{ Type of housing } & living with parents & $33(61.1)$ & $23(42.6)$ & $31(57.4)$ & $32(60.4)$ \\
\hline & others & $21(38.9)$ & $31(57.4)$ & $23(42.6)$ & $21 \quad(39.6)$ \\
\hline \multirow[t]{2}{*}{ Person who cooks } & themselves & $10(18.5)$ & $37(68.5)$ & $11(20.4)$ & $45(84.9)$ \\
\hline & others & $44(81.5)$ & $17(31.5)$ & $43(79.6)$ & $8(15.1)$ \\
\hline
\end{tabular}

tative method based on weighed-food intake records, and some items of the subject's characteristics, e.g., lactose intolerance as shown in Table 1. The amount of nutrient intake was estimated by the method used in the NNSJ using the Standard Tables of Food Composition in Japan [6]. Each subject's estimated amount of nutrient intake was described both in crude amount without energy adjustment and in nutrient density which was crude amount divided by total energy times 1000 [7]. The 1WA and the 1YA survey were identical to the BL survey.

The $\mathrm{CaE}$ was performed in the following order. Results of the NNSJ in 1991 was shown to the EC to make them understand the insufficient $\mathrm{Ca}$ intake among Japanese. They then learned to perform a self-evaluation of their eating pattern and nutritional situation observed by the BL survey and, subsequently, they were guided to set the goal for nutritional improvement by themselves. After having been exposed to a commercially available 40 minutes long videotape to appreciate what represents a sufficient $\mathrm{Ca}$ intake, they were taught how to take sufficient $\mathrm{Ca}$ intake using the Basic Foods List for sufficient Ca intake, which was developed by a group of dietitians including the present author [8]. The Basic Foods List includes 7 groups of food items, which are nutritionally well balanced, easy to take and sufficient to provide $700 \mathrm{mg}$ of Ca per day.

\section{Analytical methods}

Chi square test, analysis of variance (ANOVA) with the least square mean of Tukey-Kramer method for pair-wise comparison $\left(\mathrm{P}_{\mathrm{TK}}\right.$ indicates the $\mathrm{P}$ value obtained by this method), and Pearson's correlation coefficient $(R)$ were used to analyze difference in profile or comparability of study groups and association between items or amount of nutrients in nutrient density at BL. Multiple regression analysis (MRA) was applied to identify effect modifiers or confounders on the amount of $\mathrm{Ca}$ intake in nutrient density (ACa) at 1WA or at 1YA as the dependent variables.

Two kinds of cohort were treated as the exposure or the main independent variable, and the rest of the items, i.e., class, lactose intolerance, body mass index (BMI), person who cooks (PWC), and $\mathrm{ACa}$ at $\mathrm{BL}$ were treated as independent covariables. Interaction terms were also evaluated under the principle of hierarchically well-formulated model (HWM) and by hierarchically backward elimination approach [9] (HBE) using dummy variables for each categorical item. Analysis of covariance (ANCOVA) was used to evaluate the $\mathrm{CaE}$ effect controlling some confounders. Data analyses were conducted by the SAS software and all statistical tests were performed at the significance level of $5 \%$.

\section{RESULTS}

Demographics and comparability of cohorts at baseline

The profile of the study subjects of each cohort at the BL survey is shown in Table 1. There was no statistically significant difference between the characteristics of the two cohorts except for PWC. The composition of PWC themselves significantly varied from $18.5 \%$ to $84.9 \%$ (chi-square value $=73.4$, d.f. $=3$ ) and that of 1994 cohorts tended to be larger than that of 1993 cohorts. Table 2 shows the mean amounts of 
TABLE 2.

Mean amount of energy and nutrient intake at baseline by cohort

\begin{tabular}{|c|c|c|c|c|c|}
\hline \multirow[b]{2}{*}{ Nutrients } & \multirow[b]{2}{*}{ Unit* } & \multicolumn{2}{|c|}{ Control Cohort } & \multicolumn{2}{|c|}{ Educated Cohort } \\
\hline & & $\begin{array}{c}1993 \text { class } \\
n=54\end{array}$ & $\begin{array}{c}1994 \text { class } \\
n=54\end{array}$ & $\begin{array}{c}1993 \text { class } \\
\mathrm{n}=54\end{array}$ & $\begin{array}{c}1994 \text { class } \\
n=53\end{array}$ \\
\hline Energy & kcal & 1942 & 1828 & 1752 & 1760 \\
\hline \multirow[t]{2}{*}{ Protein } & $\mathrm{g}$ & 69.2 & 73.2 & 67.0 & 71.8 \\
\hline & & 35.9 & 40.4 & 38.2 & 40.8 \\
\hline \multirow[t]{2}{*}{ Fat } & g & 59.1 & 63.1 & 54.0 & 57.5 \\
\hline & & 30.3 & 34.4 & 30.9 & 31.4 \\
\hline \multirow[t]{2}{*}{ Carbohydrates } & $\mathrm{g}$ & 284.4 & 245.3 & 249.0 & 240.9 \\
\hline & & 146.4 & 126.3 & 128.2 & 144.0 \\
\hline \multirow[t]{2}{*}{ Calcium } & $\mathrm{mg}$ & 494.2 & 409.7 & 474.4 & 418.8 \\
\hline & & 253.4 & 223.9 & 270.0 & 241.9 \\
\hline \multirow[t]{2}{*}{ Phosphorus } & $\mathrm{mg}$ & 1008.0 & 929.0 & 970.2 & 867.1 \\
\hline & & 522.0 & 514.6 & 555.9 & 499.1 \\
\hline \multirow[t]{2}{*}{ Iron } & $\mathrm{mg}$ & 9.8 & 9.3 & 10.6 & 8.5 \\
\hline & & 5.0 & 5.2 & 6.0 & 5.0 \\
\hline \multirow[t]{2}{*}{ Vitamin A } & IU & 1924 & 1561 & 1759 & 1803 \\
\hline & & 1008 & 904 & 1016 & 1021 \\
\hline \multirow[t]{2}{*}{ Vitamin $B_{1}$} & $\mathrm{mg}$ & 0.94 & 0.85 & 0.90 & 0.80 \\
\hline & & 0.49 & 0.47 & 0.52 & 0.47 \\
\hline \multirow[t]{2}{*}{ Vitamin $B_{2}$} & $\mathrm{mg}$ & 1.21 & 1.02 & 1.14 & 1.02 \\
\hline & & 0.68 & 0.57 & 0.63 & 0.58 \\
\hline \multirow[t]{2}{*}{ Vitamin C } & $\mathrm{mg}$ & 58.1 & 52.9 & 56.7 & 72.5 \\
\hline & & 29.5 & 30.4 & 33.2 & 39.0 \\
\hline
\end{tabular}

* The upper row of each nutrient shows crude amount of intake and the lower row shows those in nutrient density.

energy intake and the intake of each nutrient in terms of crude amount and nutrient density at BL by cohort. Overall differences of intake of energy and of each nutrient among the 4 study groups were not statistically significant by ANOVA except for ener$\mathrm{gy}$, fat and $\mathrm{Ca}$. Although differences in energy intake were significant $(\mathrm{F}=2.84$, d.f.s $=3,211, \mathrm{P}=0.039)$, pair-wise differences were insignificant. Differences in fat intake were significant $(\mathrm{F}=3.68$, d.f. $\mathrm{s}=3,211$, $\mathrm{P}=0.013$ ) and the mean amount of fat intake by the $1993 \mathrm{CC}, 30.3 \mathrm{mg}$, was significantly smaller than the fat intake of $34.4 \mathrm{mg}$ by the $1994 \mathrm{CC}\left(\mathrm{P}_{\mathrm{TK}}=\right.$ 0.015). Differences in ACa were significant $(\mathrm{F}=3.05$, d.f.s $=3,211, \mathrm{P}=0.030$ ), the mean $\mathrm{ACa}$ by the 1993 $\mathrm{EC}, 270.0 \mathrm{mg}$, was larger than the $223.9 \mathrm{mg}$ by the $1994 \mathrm{CC}\left(\mathrm{P}_{\mathrm{TK}}=0.019\right)$. ACa at BL partly correlated with the intake amount of other nutrients, e.g., with protein among the $1993 \mathrm{CC}(\mathrm{R}=0.368, \mathrm{P}=0.006)$, with phosphorus among the $1993 \mathrm{EC}(\mathrm{R}=0.315$, $\mathrm{P}=0.020$ ), and with vitamin $\mathrm{B}_{2}$ among the $1994 \mathrm{EC}$ $(\mathrm{R}=0.374, \mathrm{P}=0.005)$. Person not living with their parents significantly tended to be PWC themselves in cohorts (chi-square value ranged from 5.00 to 18.41 , d.f.=1) except for the 1993 EC.

Secular trend of crude intake of energy and each nutrients except calcium at 3 surveys by cohort

The figure on each upper row in Table 2 shows the mean amount of energy and the crude mean amount of nutrient intake at BL by cohort. The CC decreased intake of energy, protein, carbohydrates, fat and iron, but the other nutrients except Ca showed insignificant secular trends of intake during the term from BL through 1YA. The EC, on the other hand, decreased the intake of energy, carbohydrates and iron but fat intake at 1WA was 15\% larger than that at $\mathrm{BL}$ and almost returned to the BL level at 1YA. Other nutrients except $\mathrm{Ca}$ did not show significant secular trends in the EC.

Comparing these figures to the RDA for Japanese 18 -year-old female engaging in light or moderate levels of physical activity, CC subjects fulfilled 95\%, $110 \%, 84 \%, 116 \%$ and $71 \%$ of the RDA for energy, protein, carbohydrates, fat and iron, respectively, on 
the average of the 3 surveys. Phosphorus and vitamins were adequately taken by these subjects. The fat energy ratio (FER) of CC subjects at BL, 1WA or 1YA was 29,32 or $30 \%$, respectively, and these FERs were all above the RDA of $20-25 \%$.

The EC fulfilled 94\%, 114\%, 83\%, 113\%, $75 \%$ of the RDA for energy, protein, carbohydrates, fat and iron, respectively. The phosphorus intake was almost at the upper limit of the RDA, on the average of the 3 surveys.

Secular trend of amount of calcium intake at 3 surveys by cohort

The crude intake of $\mathrm{Ca}$ among $\mathrm{CC}$ at $1 \mathrm{WA}$ was $3 \%$ larger than at BL and 6\% larger than at 1YA. In contrast, the Ca intake among EC at 1WA was $21 \%$ larger than at $\mathrm{BL}$ and at $1 \mathrm{YA}$ maintained a level $11 \%$ larger than at BL. The $\mathrm{CC}$ and $\mathrm{EC}$ fulfilled $77 \%$, or $83 \%$ of the RDA for $\mathrm{Ca}$ on the average at 3 surveys, respectively.

The ACa by cohort at the 3 surveys is shown on each lower row in Table 3. The ACa in general increased during the study period. The 2 way ANOVA on 1) the increments of ACa between 1WA and $\mathrm{BL}$, and those between 1YA and 1WA, and 2) class of admission year for the 2CCs indicated significant interaction $(\mathrm{F}=6.32$, d.f.s $=1,1, \mathrm{P}=0.013)$ but subsequent pair-wise comparisons were insignificant. On the other hand, the $\mathrm{ACa}$ at $\mathrm{BL}$ significantly correlated with $\mathrm{ACa}$ at $1 \mathrm{WA}(\mathrm{R}=0.357, \mathrm{P}=0.008$, for $1993 \mathrm{CC} ; \mathrm{R}=0.452, \mathrm{P}=0.001$, for $1993 \mathrm{EC} ; \mathrm{R}=0.332$, $\mathrm{P}=0.014$, for $1994 \mathrm{CC}$ ) and $\mathrm{ACa}$ at 1WA correlated with ACa at 1YA ( $\mathrm{R}=0.308, \mathrm{P}=0.023$ for $1993 \mathrm{CC})$.

With regard to $\mathrm{Ca}$ source, the $\mathrm{CC}$ took Ca mainly from milk and dairy products $(45.6 \%)$, vegetables $(10.0 \%)$, pulses $(8.4 \%)$ or fishes and shellfishes $(5.4 \%)$ at BL and a similar trend persisted at 1WA and 1YA. Although the EC mainly took $\mathrm{Ca}$ from these four kinds of food groups at both BL and 1YA, the amount of $\mathrm{Ca}$ intake from the latter three kinds of food groups at 1WA was significantly increased.

\section{Effect of calcium education on amount of calcium intake}

PWC was used for the initial MRA rather than type of housing because of its significant correlation with type of housing. Initial MRA on the HWM for identifying effect modifier or confounder on $\mathrm{ACa}$ at 1WA and the following HBE procedures revealed that all of the 2nd or the 1st order interaction terms, items of class, BMI, or PWC turned out to be insignificant. By contrast, the terms of cohort $(\mathrm{F}=4.51$, d.f. $=1, \mathrm{P}=0.035), \mathrm{ACa}$ at $\mathrm{BL}(\mathrm{F}=18.73$, d.f. $=1, P=0.000)$ and lactose intolerance $(F=6.57$, d.f. $=1, P=0.011)$ turned out to be significant items. The following ANCOVA showed that the mean ACa of EC at 1WA, $296.1 \mathrm{mg}$ was significantly larger than that of CC, $267.4 \mathrm{mg}$, controlling the effect of $\mathrm{ACa}$ at $\mathrm{BL}$ and lactose intolerance.

Similar analysis for identifying effects modifiers or confounders on $\mathrm{ACa}$ at 1YA revealed that terms of class and lactose intolerance were only the significant items and the following ANCOVA showed that the mean ACa of EC at $1 \mathrm{YA}, 315.7 \mathrm{mg}$ was not significantly larger than that of $\mathrm{CC}, 305.5$ $\mathrm{mg}$, controlling the effect of class and lactose intolerance.

TABLE 3.

Secular trend of amount of calcium intake by cohort at three surveys

\begin{tabular}{lccccc}
\hline \multirow{2}{*}{ Survey } & \multicolumn{2}{c}{ Control Cohort } & & \multicolumn{2}{c}{ Educated Cohort } \\
\cline { 2 - 3 } \cline { 5 - 6 } & $\begin{array}{c}1993 \text { class } \\
\mathrm{n}=54\end{array}$ & $\begin{array}{c}1994 \text { class } \\
\mathrm{n}=54\end{array}$ & & $\begin{array}{c}1993 \text { class } \\
\mathrm{n}=54\end{array}$ & $\begin{array}{c}1994 \text { class } \\
\mathrm{n}=53\end{array}$ \\
\hline \multirow{2}{*}{ Baseline } & 494.2 & 409.7 & & 474.4 & 418.8 \\
& 253.4 & 223.9 & & 270.0 & 241.9 \\
1 week after the calcium education & 487.1 & 441.7 & & 539.4 & 545.8 \\
\multirow{2}{*}{ 1 year after the calcium education } & 265.5 & 259.6 & & 300.1 & 301.8 \\
& 491.0 & 465.1 & & 511.7 & 483.7 \\
\cline { 5 - 6 } & 331.8 & 274.1 & & 364.4 & 271.2 \\
\hline
\end{tabular}

* The upper row of three surveys shows crude amount of intake and the lower row shows those in nutrient density. 


\section{DISCUSSION}

The present study was not a randomized control trial but a prospective cohort study. Since the EC as the exposed cohort and the $\mathrm{CC}$ as the non-exposed cohort consist of the 2 classes due to different admission years, comparability among the 4 study groups is a crucial point. The profiles of the 4 potential confounders were comparable among the 4 study groups at BL except for PWC. The nutritional situation in terms of nutrient intake at BL showed overall comparability among the 4 study groups except for intake of energy, fat and Ca. Significant pair-wise differences of fat intake between 1993 CC and $1994 \mathrm{CC}$ and of $\mathrm{Ca}$ intake between $1993 \mathrm{EC}$ and 1994 CC, however, may not be meaningful differences, because each nutrient should be compared between EC and CC in the same class of admission year. On the other hand, the fact of positive association of $\mathrm{ACa}$ between the 3 surveys may indicate the necessity of preceding $\mathrm{ACa}$ being treated as potential confounders in order to evaluate effect of $\mathrm{CaE}$ on subsequent $\mathrm{ACa}$. This means that $\mathrm{ACa}$ at 1WA might be influenced by study group, lactose intolerance and $\mathrm{ACa}$ at $\mathrm{BL}$ and the latter 2 variables should be treated as confounders to evaluate the effect of study group on ACa at 1WA.

In the present study, the amount of $\mathrm{Ca}$ intake was described in both crude amount and nutrient density. Although the latter procedure has been used and investigated since 1986 [7], and its nutritional significance may not have been established [10], the statistical analyses were based on the nutrient density for the present study.

A response bias due to the assignment to either $\mathrm{CC}$ or EC was not likely because of the blind assignment of the subjects and of the similar pattern of energy and some nutrient intake against RDA between the two cohorts, i.e., insufficient intake of energy, carbohydrates, $\mathrm{Ca}$, iron and over intake of protein, fat and phosphorus.

Both EC and CC took excessive amount of fat and insufficient amount of iron at the 3 surveys and EC consumed a particularly increased amount of fat along with the increased $\mathrm{ACa}$ at 1WA. These relatively excessive fat and insufficient iron intakes were not preferable according to the RDA and if EC strictly followed the Basic Food List after the CaE, the pattern of their nutrient intake at 1WA or at 1YA must have been much closer to the RDA. This means that the present $\mathrm{CaE}$ might have put more stress on encouraging a well-balanced intake of foods in the Basic Food List.

The present study may indicate some effect of the present $\mathrm{CaE}$ on the present $\mathrm{EC}$, however, the extent of the effect was not large enough to make EC to fulfill the RDA of $\mathrm{Ca}$ and the effectiveness may subside over the time. The present $\mathrm{CaE}$ further needs to be investigated from the point of view of materials for $\mathrm{CaE}$, ways of presentation, and other aspect of behavioral science, and therefore it is premature to infer any possible applicability of the present $\mathrm{CaE}$ to an external population.

ACKNOWLEDGMENTS: The author wishes to express her great thanks to Professor Katsuhiro Fukuda, M.D., Ph.D. and Associate Professor Akira Shibata, Ph.D. (Department of Public Health, Kurume University School of Medicine) for their thoughtful comments, and also thanks Ms. Noriko Hashimoto and Ms. Naomi Handa for their kind assistance.

\section{REFERENCES}

1. Japanese Ministry of Health and Welfare. National Nutritional Survey of Japan in 1992. Dai-ichi-Syuppan, Tokyo, 1993. (in Japanese)

2. Japanese Ministry of Health and Welfare. Recommended Dietary Allowances for the Japanese. Dai-ichi-Syuppan, Tokyo, 1993. (in Japanese)

3. Okazaki M, Katouno S, Kido K, and Oku T. Attempts for nutrition education on osteoporosis and calcium intake for elderly women. J Nutr 1997; 55:273-282.

4. Miyamura T, and Asaka A. Effect of measuring bone mineral density on calcium intake. Jpn J Geriatrics 1996; 33:840-846.

5. Sueta K, and Fukuda K. Epidemiological assessment of an intervention trial to increase calcium intake in female college students. Kurume Med J 1995; 42:275-279.

6. Science and Technology Agency, Japan. Standard Table of Food Composition in Japan, The Fourth edn, Ministry of Finance, Tokyo, 1982. (in Japanese)

7. Willett CW, and Stampfer MJ. Total Energy Intake: Implications for Epidemiologic Analyses. Am J Epidemiol 1986; 124:17-27.

8. Hachou Y, Koyama M, Nose R, Sueta K, Sugitani M et al. A prevention trial for osteoporosis, 4th report. Proceedings of the Japan Society of Cookery Science $1990 ; 48$.

9. Kleinbaum DG. Statistics in the Health Sciences, Logistic Regression. Springer-Verlag New York Inc, New York, 1994.

10. Willett CW, Howe GR, and Kushi LH. Adjustment for total energy intake in epidemiologic studies. Am J Clin Nutr 1997; 65:1220s-1228s. 